\title{
DESVENDAR O ESTADO: ABORDAGEM NECESSÁRIA NA DEFINIÇÃO DE ESTRATÉGIAS QUEER/FEMINISTAS
}

\author{
Naira Pinheiro dos Santos*
}

Resenha de: MÖSER Cornelia; TILLOUS, Marion (textes choisis et présentés par). Avec, sans ou contre. Critiques queers/féministes de l'État. Donnemarie-Dontilly: Éditions iXe. Collection racine de iXe, 2020, 292p.

Nos últimos anos temos visto diversos Estados nacionais, como é claramente o caso do Brasil, "cederem" às pressões de grupos religiosos conservadores ou fundamentalistas no sentido de bloquear e/ou retroceder nas pautas e políticas de igualdade de gênero, direitos sexuais e reprodutivos, reivindicadas por grupo feministas e LGBTQI. Para além do papel das religiões, tal situação evoca a responsabilidade do Estado ou Estados nacionais e/ou de suas instituições, levando-nos a pensar se, como denuncia o coletivo chileno "Las Tesis" em sua performance", executada em diversos países, os policiais, os juízes, o presidente e o próprio Estado não seriam machos violadores. Ao incluir esse trecho do texto da performance na epígrafe da introdução, Cornelia Möser e Marion Tillous apontam para o questionamento que perpassa a presente obra: o que é e qual o lugar que o Estado ocupa na produção de estruturas sexistas, que relações as lutas queer/feministas estabeleceram ou estabelecem com o Estado e quais são o(s) posicionamento(s) estratégico(s) que melhor convêm às lutas queer/feministas?

A presente obra foi organizada por Cornelia Möser, pesquisadora do CNRS, membro do laboratório Genre, Travail, Mobilités - GTM/ CRESPPA e pesquisadora associada do Centro Marc Bloch de Berlin (Alemanha) e Marion Tillous, professora-pesquisadora na área de geo-

\footnotetext{
* Doutora em Ciências da Religião, membro do grupo de pesquisa em gênero e religião Mandrágora/NETMAL e membro da equipe editorial da revista Mandrágora.

1 Un violador em tu camino. Performance do coletivo Las Tesis, Santiago do Chile, 25 de novembro de 2019. Disponível em: < https://www.youtube.com/watch?v=yJGEgzqgna8 >.
} 
grafia e estudos de gênero da Universidade de Paris 8, no âmbito do Laboratoire d'Études de Genre et Sexualité - UMR LEGS. A escolha do termo queer/feministas é justificada pelas organizadoras não só pelo caráter desestabilizador de normas e categorias tradicionais de gênero e sexualidade do pensamento queer, como pelo fato de que, com esse slash, pretende-se recusar uma determinada clivagem entre o feminismo radical, que se ocuparia das violências sexuais, e o movimento queer, que se ocuparia do prazer sexual. Ademais, como apontam as autoras, "as políticas sexuais não podem ser reduzidas a políticas de gênero e as políticas de gênero também não se reduzem a políticas sexuais" (p. 25).

Motivadas pelo inconformismo com uma suposta necessidade de escolher "entre buscar uma institucionalização perfeita do feminismo ou recusar categoricamente toda forma de institucionalização" ( $p$. 22), e a fim de contribuir para uma crítica queer/feminista do Estado, Cornelia Möser e Marion Tillous buscaram, através de pesquisa bibliográfica e da organização de um seminário na Universidade de Paris 8 , estabelecer o estado da arte e analisar as diferentes abordagens e críticas queer/feministas do Estado. Em ambos os casos, guiaram-se por três objetivos: compreender, desde uma perspectiva histórica, como o Estado-nação moderno se constituiu e qual o papel do gênero e da sexualidade nesse processo; apreender a estrutura e o funcionamento do Estado e como, desde uma perspectiva interseccional, o gênero e a sexualidade intervém aí; identificar e refletir sobre outras maneiras de empreender políticas feministas, práticas coletivas alternativas ao Estado, utópicas, contraexemplares e estruturas anti-institucionais. A presente obra é constituída de uma entrevista e cinco artigos, dentre os quais um relatório de pesquisa, uma proposta teórica, um estudo de caso e a tradução de dois textos históricos.

No primeiro artigo, Les critiques queer/féministes de l'État (As crítica queer/feminista" do Estado), Cornelia Möser e Marion Tillous pontuam que, para efetuar uma crítica quer/feminista do Estado, é necessário primeiro compreendê-lo e, para tanto, apoiaram-se em pesquisa bibliográfica segundo os três objetivos propostos, conforme exposto mais

O programa do seminário, que teve lugar no primeiro semestre de 2018, encontra-se disponível em: < https://cqfde.hypotheses.org $>$. 
acima. Elas tratam, portanto, de deslindar e aprofundar a compreensão acerca do que seria efetivamente o Estado, perguntando-se, inicialmente, como ele atua ou deixa de atuar no que se refere às políticas sexuais, à administração do gênero, ao casamento, à família e à separação das esferas pública e privada e como se constitui o Estado Moderno, para posteriormente abordar as formas de organização e possíveis estratégias de luta queer/feminista.

As autoras denunciam o papel ativo do Estado, cujas políticas sexuais não se limitam às políticas demográficas e de controle populacional. Suas políticas sexuais e de administração do gênero, através de diversos dispositivos de categorização dos indivíduos, tais como documentos de identidade e leis que condenam ou autorizam certas práticas sexuais, se configuram como tecnologias de poder, que investem na produção dos sujeitos através do sexo, e como instrumentos de controle e de segregação entre "pessoas que merecem proteção e aquelas que representam uma ameaça” (p. 28): pobres, imigrantes, pessoas trans e intersexo.

As autoras avaliam que, uma vez que o mesmo Estado de bem-estar social é o responsável por garantir a segurança pública, as contradições entre políticas repressivas e de bem-estar social afetam de modo mais intenso alguns grupos/pessoas em detrimento de outros/as. Assim sendo, um dos riscos que se corre ao trabalhar com o Estado é o de que certas leis não produzam os resultados pretendidos na redução de relações de dominação, ao mesmo tempo em que lhe possibilitam "reforçar o seu sistema de controle e de punição, sem que as instituições sejam questionadas" (p. 55). Elas evocam a pesquisa de Dean Spade 3 para apontar que, mesmo na presença de leis igualitárias, o acesso de pessoas não cisgênero a inúmeros serviços segue sendo limitado pelo fato destes serem ainda frequentemente estruturados de forma binária e segregada por sexo.

Cornelia Möser e Marion Tillous destacam a necessidade de contemplar também as tensões entre a história colonialista e patriarcal do Estado (e de fazer distinção entre Estados colonialistas e ex-colônias,

SPADE Dean. Normal life. Administrative violence, critical trans politics, and the limits of law. New York: South End Press, 2011. 
autoritários ou democráticos, monárquicos, presidencialistas ou parlamentaristas, por exemplo, tendo em conta também as relações de poder entre estados nacionais) e as diversas tentativas de transformá-lo através da institucionalização das lutas contra a dominação. Elas destacam a existência de analogias entre as formas de poder no seio conjugal, das famílias, dos clãs e do Estado, algo que seria evidenciado, por exemplo, pelo "acordo tácito entre o Estado e os homens, aos quais ele confere uma parte da violência legítima em troca da paz social”, conforme aponta o artigo de Birgit Sauer, traduzido e publicado no livro. Ora, a própria gênese do Estado moderno, "capitalista, colonialista e patriarcal”, teria se dado em base a "uma guerra contra as mulheres, a caça às bruxas, e ao mesmo tempo através da expropriação do campesinato europeu e da colonização" (p. 39). Evocam a obras de Silvia Federici ${ }^{4}$ (2014) e de Eleni Varikas 5 (2000) para pontuar que, não obstante não se possa negligenciar o papel da Igreja Católica, particularmente no que concerne à provisão dos fundamentos ideológicos da caça às bruxas, esta não teria sido possível sem um Estado forte para fazer face "à generalização da luta antifeudal e preservar as relações de classe” (p. 41). A heterodoxia religiosa e política, bem como as práticas sociais dissidentes, haviam se tornado um fenômeno de massa na Europa do século XVI, e contavam com ampla participação das mulheres, de modo que a heresia teria sido "esmagada não tanto por motivos religiosos, mas porque ela desafia as pretensões unificadoras do poder temporal” (p. 41). Tal processo teria possibilitado consolidar as instituições e estruturas do Estado absolutista e generificado, bem como o poder dos Estados colonizadores sobre os Estados colônias. Nesse contexto, racismo, nacionalismo e sexualidade constituiriam uma matriz a partir da qual se criam regimes sexuais e de gênero diferenciados e se estabelece o acesso ou não de pessoas ao estatuto de sujeitos.

4 FEDERICI, Silvia. Caliban et la sorcière. Femmes, corps et accumulation primitive. Marseille, Genève, Paris : Senonevoro \& Entremonde, 2014 [2004].

5 VARIKAS, Eleni. Naturalisation de la domination et pouvoir légitime dans la théorie politique classique. In: GARDEY, Delphine; LÓWY, Ilana (Dir.). L'Invention du naturel. Paris: POL, 2000, p. 89-108. 
No que concerne às possibilidades de estratégias de luta, as autoras tratam de resgatar experiências utópicas contraexemplares e/ ou anti-institucionais, algumas menos coibidas, outras mais radicais e brutalmente reprimidas que, por este motivo, tenderiam a ser menos efetivas. Elas privilegiam as estratégias alternativas, práticas feministas políticas e coletivas independentes do Estado, considerando que a busca por direitos no plano legal estaria limitada pelo fato de que as leis tendem a reforçar o status quo e que, mesmo que batalhas tenham sido ganhas, "isso se dá sempre dentro de relações de força desiguais" ( $p$. 60). Ainda assim, elas reconhecem que nem sempre as estratégias de luta voltadas para o Estado (com ou contra) significaria que se deixa de criticá-lo. Chegam mesmo a apontar o "entrismo" como alternativa inescapável aos olhos de algumas mulheres, a saber, aquelas "nascidas do lado das dominadas [..] a única maneira de deixar o lugar que lhes foi designado e se fazer ouvir" (p. 53).

Consideramos que tal afirmação, no entanto, deixa margem a alguns questionamentos: o que faltaria a essas mulheres que não lhes possibilitaria pensar e empreender lutas alternativas, sem e/ou contra o Estado e/ou o que faria com que este tivesse uma postura tal em relação a elas, que Ihes possibilitasse obter mudanças efetivas, diferentemente das demais? Os movimentos queer/feministas são estruturados de modo identitário e/ou excludente, cada grupo buscando unicamente seus próprios interesses? E se, por um lado a perspectiva interseccional é cara às críticas e lutas queer/feministas, como o reconhecem as autoras, por outro lado, considerar a institucionalização e/ou entrismo como alternativa à qual apenas um grupo específico de mulheres não se poderia furtar não promoveria um tipo de estratificação?

Interessante destacar, finalmente, que no que concerne à religião, as organizadoras a abordam como fenômeno multifacetado, diverso, evocando, por exemplo, o papel das heresias na luta antifeudal. Apontam que, se é fato que "é muito frequentemente através da instituição da família que o Estado governa os/as cidadãos/ãs e que a Igreja - como outras instituições religiosas - participa ativamente da construção das famílias heteropatriarcais" (p. 63), verifica-se também, historicamente, a mobilização de um poder contra o outro pelos grupos queer/feministas. 
Dentre outros exemplos, citam a mobilização do braço legislativo do Estado contra o poder da Igreja (no que se refere a direitos sexuais e reprodutivos, por exemplo), da família contra a violência estatal, como é o caso "do método proposto pelo coletivo de mulheres racializadas 'Incite!', face à violência assassina da polícia nos Estados Unidos” (p. 63) ou, ainda, a mobilização "da Igreja contra o poder tirânico do pai de família" ( $p$.63) assim como da religião contra o Estado, como "por exemplo, na Polônia, no Irã, ou em muitos Estados colonialistas que foram atacados pelas teologias da libertação" (p. 64).

O artigo de Davina Cooper, Des identités multiples. La Sexualité et l'État en lutte, foi extraído e traduzido do livro de sua autoria intitulado "Power in Struggle: Feminism, sexuality and the State" (1995). A autora parte de diversos conceitos e formas de abordar o Estado - ou seja, como um bloco unitário, ou como um vasto sistema de instituições e relações, diferenciado e contraditório, ou ainda atravessado por especificidades, nuances, cheio de continuidades e similaridades -, para propor uma concepção não essencialista de Estado e percebê-lo como um fenômeno multifacetado, "articulado de maneira contingente e sem forma, essência ou núcleo fixo” (p. 92). A conexão entre as suas múltiplas identidades e a preponderância de uma sobre as outras em determinado momento dependeria do contexto e/ou "do quadro discursivo através do qual o Estado é construído e “lido”" (p. 92). Davina Cooper propõe que, não obstante se reivindique assexuado, diversos aspectos da identidade do Estado são moldados pela sexualidade, sobretudo enquanto poder disciplinar, e analisa as características sexuais específicas que o integram. A autora conclui que as relações entre o Estado e a sexualidade são múltiplas e mutáveis, sujeitas aos efeitos de "princípios organizadores tais como a raça, o gênero e a classe, o poder dos indivíduos e de forças sociais influentes (quer venham do mundo econômico, da Igreja ou dos sindicatos) e [...] de outros campos em interação (o campo cultural ou a economia internacional, por exemplo)" (p. 120,121).

Em Les femmes, les migrant-es et l'Europe, Rada Ivekovic analisa a resistência das nações europeias a reconhecer às mulheres e a outros grupos subalternos, particularmente estrangeiros/as, migrantes e refu- 
giados/as, os direitos ditos universais e os benefícios do Estado Providência. A autora evoca a história colonialista da Europa e as similitudes entre o Estado moderno/nação e as religiões monoteístas, especialmente no que concerne à sua estrutura patriarcal, para denunciar a armadilha identitária: a inclusão dos/as outros/as requer a sua assimilação aos/às dominantes, enquanto "os/as outros/as, ao mesmo tempo em que recusam as características que os/as dominantes lhes atribuem, se veem na contingência de reivindicá-las para ter, paradoxalmente, acesso à universalidade, guardando, no entanto a sua particularidade" (p. 124). Na perspectiva da autora, as políticas identitárias jogam contra migrantes e refugiados/as, como também contra as mulheres. Propõe como estratégia, portanto, o aprofundamento da solidariedade entre mulheres e migrantes e a reconstrução de uma espiritualidade envolvendo a karunã budista. Na perspectiva da autora, esta possibilitaria reconhecer a interdependência e estabelecer uma empatia tal que cobriria os diversos marcadores sociais e identitários, favorecendo assim a desidentificação.

No artigo subsequente, intitulado Les politiques du genre de l'État égyptien. Histoire et enjeux de la reconaissance du harcélement sexuel em Egypte, Perrine Lachenal aponta que, desde os anos 50, por pressão do movimento feminista, a "causa das mulheres" passou a fazer parte das políticas de estado no Egito, de modo que a categoria "feminismo" está historicamente imbricada às estruturas do poder. Através da história da luta contra o assédio sexual, ela evidencia os limites da ação estatal na luta feminista contra este. Ao mesmo tempo em que o Estado reconhece a existência do assédio, procura despolitizá-lo através da criminalização individual, e instrumentaliza a luta como meio de controle social de homens de classes populares e de mulheres que contrariam a moral pública. A autora aponta as ambiguidades que atravessam os discursos nacionalistas egípcios acerca do lugar das mulheres ou do "feminismo de estado", assim como os limites da ação institucional e associativa, que se vê na contingência de uma despolitização estratégica dos discursos, a fim de obter financiamentos internacionais e evitar "provocar a desconfiança do Estado "(p. 165), para poder seguir lutando. Destaca, contudo, que a ação feminista das ONGs não deve ser ignorada e que a inscrição de questões sensíveis, 
como as das violências conjugais, da excisão e do divórcio na agenda política, deve-se à sua incessante atuação.

O último artigo do livro consiste na tradução de um clássico, um dos primeiros da literatura feminista germanofônica sobre o tema do Estado, que as coordenadoras consideraram conveniente disponibilizar ao público francofone. Trata-se do artigo de Birgit Sauer, La violence de genre dans IÉtat de droit et son institutionnalisation dans l'Etat-providence. Pour une réflexion sur le genre en science politique. A autora considera que, nas ciências políticas, existe uma lacuna no que se refere ao próprio conceito de violência e, particularmente, ao de violência de gênero. Ela destaca o aspecto complexo e multifacetado da violência de gênero, a qual não se limita ao seu aspecto físico, mas a todas as dimensões que constituem a identidade e a qualidade de um ser humano. Esta deve ser entendida desde um ponto de vista de relações sociais que produzem a vulnerabilidade das mulheres, e que só pode ser combatida numa perspectiva de erradicação das relações de dominação. Na perspectiva da autora, os discursos hegemônicos produzem a violência, e "o Estado é um campo hegemônico e um 'discurso hegemônico' que privilegia, marginaliza e desarticula certos interesses ou identidades" (p. 190). Postula, ainda, que o Estado é masculino, na medida em que sua configuração moderna se estabelece num contexto masculino e hegemônico. Conclui que o mesmo ocorre com o Estado Providência, na medida em que este se estabeleceu, inicialmente, sobre o modelo do "macho provedor" e, ainda que no pós-guerra se verifique uma inflexão na política social, mais centrada no indivíduo, persiste o foco no trabalho remunerado, espaço privilegiadamente masculino.

O livro finaliza com a entrevista de Cornelia Möser e Jana Tschurenev com Dorothea Dornhof e Karin Aleksander, intitulada De l'État socialiste à l'État capitaliste. Perspectives féministes d'Allemagne de l'Est. Entretien avec Dorothea Dornhof e Karin Aleksander. A intenção das coordenadoras com esta entrevista foi a de contribuir com a reflexão sobre as diferenças entre os diversos tipos de Estado e sobre as relações históricas, políticas e econômicas que os Estados entretêm uns com os outros. As entrevistadas, nascidas ambas na Alemanha Oriental, a hoje inexistente República Democrática Alemã (RDA), apontam que 
a abordagem nesse contexto era tradicionalmente marxista, ou seja, apregoava que a emancipação feminina dependia unicamente da integração das mulheres ao mercado de trabalho remunerado, integração que, ademais, constituía uma necessidade do Estado socialista no pós-guerra. Dorothea Dornhof pontua que ali "não houve feminismo de Estado porque, na realidade, o feminismo significa outra coisa e essa palavra, na tradição do Leste Europeu [...] era considerada como pertencente a uma ideologia burguesa" (p. 220). O movimento feminista na RDA se organizou no seio da Igreja, em torno de grupos de lésbicas, que, muitas vezes, eram também eram hospedadas pela Igreja, e de mulheres pela paz. As entrevistadas apontam que, ainda que não tenha havido uma política de mudança das relações tradicionais de gênero, as creches eram amplamente disponíveis na Alemanha Oriental. Assim, por ocasião da unificação, a proporção de mulheres ocupando postos remunerados no mercado de trabalho era de cerca de 90\% na Alemanha Oriental contra $50 \%$ na Alemanha Ocidental, visto que a disponibilidade de creches aí era muito menor e com horários mais restritos. Ademais, ainda que objetivando afirmar a sua superioridade frente à Alemanha Ocidental, a RDA cedeu às pressões das mulheres e descriminalizou o aborto. Cornelia Möser e Jana Tschurenev destacam que, na Alemanha Ocidental, ocorria o contrário, o aborto era ilegal por ocasião da unificação. Ainda de acordo com Cornelia Möser e Jana Tschurenev, a "política natalista fundamentalista promovida pelo Estado e pela religião podia, e ainda pode, se contrapor ao desejo de ter filhos/as, uma vez que [... tal desejo] não é amparado por condições materiais aceitáveis" (p. 215).

Enfim, de acordo com as coordenadoras da obra, as pesquisas sobre relações que atravessam o Estado moderno são mais ou menos desenvolvidas, de acordo com o contexto, sendo que nem sempre são suficientemente levadas em conta. A presente obra constitui uma importante contribuição nesse sentido, ao demonstrar que desvendar o Estado constitui efetivamente uma necessidade na definição de estratégias queer/feministas.

Parece-nos, contudo, que há, particularmente da parte das coordenadoras, uma sobrevalorização do poder como algo primordialmente concentrado no e emanado do Estado e no qual as relações de poder 
mudariam apenas para ficar iguais (p. 38). Resulta daí uma visão acentuadamente pessimista quanto a estratégias de luta com o Estado, embora considerem que pode haver diferenças entre um e outro tipo de Estado. Em grande medida, parece que é sempre o Estado a fonte de poder, transmitindo-o seja ao homem no seio da família, às/aos/ professoras/es nas escolas ou às instituições religiosas, dentre outras. Talvez tal perspectiva se deva ao esforço necessário para quebrar paradigmas consolidados quanto à concepção, estrutura e funções do Estado e/ou de abranger e conciliar perspectivas teóricas que, sob certos aspectos, nem sempre são reconciliáveis. Com efeito, ainda que evoquem frequentemente uma perspectiva foucaultiana de poder, as organizadoras a mobilizam mais para afirmar a capacidade de lutar fora ou contra o Estado, enquanto a perspectiva althusseriana de Estado, "um tanto quanto totalizante" (p. 63) e que vê a Igreja e a família heteropatriarcal como seus aparelhos ideológicos, parece levar a melhor no que se refere à concepção deste e/ou às relações que o constituem e o atravessam. As organizadoras reconhecem que há uma contradição entre essas duas perspectivas, embora considerem que é possível superá-la por meio da abordagem de Davina Cooper, segundo a qual “o Estado possui múltiplas identidades que são todas, apesar da sua diversidade, aquelas de uma só e mesma 'pessoa"' (p. 59).

Ainda que se possa notar certo viés ou contradições na análise, conforme apontamos, a própria concepção da obra, que trata de integrar e unir as críticas queer e feminista para destacar a necessidade de abordar, de forma ampla e complexa, os vários aspectos e tessituras do poder do Estado - sua formação, seu funcionamento, seus braços, suas articulações com outras instâncias de poder, além do fato de colocar em evidência diversas experiências alternativas de luta -, sem dúvida faz dela uma importante contribuição para as pesquisas e para as práticas queer/feministas. 


\section{REFERÊNCIAS}

FEDERICI, Silvia. Caliban et la sorcière. Femmes, corps et accumulation primitive. Marseille, Genève, Paris: Senonevoro \& Entremonde, 2014 [2004].

SPADE Dean. Normal life. Administrative violence, critical trans politics, and the limits of law. New York: South End Press, 2011.

VARIKAS, Eleni. Naturalisation de la domination et pouvoir légitime dans la théorie politique classique. In: GARDEY, Delphine; LÓWY, Ilana (Dir.). L'Invention du naturel. Paris: POL, 2000, p. 89-108.

Un violador em tu camino. Performance do coletivo Las Tesis, Santiago do Chile, 25 de novembro de 2019. Disponível em: < https://www.youtube.com/watch?v=yJGEgzqgna8 >.

Submetida em: 1-9-2021

Aceita em: 22-11-2021 
